\title{
ENRAIZAMIENTO DE VITROPLANTAS DE MEMBRILLO (Cydonia oblonga) POR MEDIO DE INMERSIÓN TEMPORAL AUTOMATIZADA Y SU ACLIMATACIÓN ${ }^{1}$
}

\author{
DORA FLORES MORA², RANDALL CHACÓN CERDAS ${ }^{3}$, LUIS ALVARADO MARCHENA ${ }^{4}$, \\ ALEXANDER SCHMIDT DURÁN ${ }^{5}$, CARLOS ALVARADO ULLOA ${ }^{6}$
}

\begin{abstract}
RESUMEN - El membrillo (Cydonia oblonga) es un frutal no tradicional en Costa Rica que presenta propiedades médicas y nutricionales, sin embargo la lentitud del crecimiento y enraizamiento dificulta obtener poblaciones homogéneas mediante técnicas convencionales. Es por esta razón que esta investigación tuvo como objetivo la producción de material vegetal uniforme en tiempos reducidos empleando sistemas de inmersión temporal $\left(\right.$ RITA $\left.^{\circledR}\right)$. Se utilizó como referencia un medio de enraizamiento semisólido MS, suplementado con $0,1 \mathrm{mg} \mathrm{L}^{-1}$ ANA; $0,3 \mathrm{mg} \mathrm{L}^{-1}$ AIB y 3\% de sacarosa a un $\mathrm{pH}$ de 6,5; desarrollado por el Centro de Investigación en Biotecnología (CIB), del Instituto Tecnológico de Costa Rica (ITCR), en Cartago. Se realizaron cuatro variaciones en la concentración de sacarosa $(1 \%, 2 \%, 3 \%$ y 4\%) en medio líquido. Cada ensayo fue evaluado con vitroplantas previamente expuestas al medio correspondiente empleado en los tratamientos, de forma estacionaria por un período de 15 días, y con vitroplantas sin tratamiento previo (ocho tratamientos en total). La comparación de los porcentajes de enraizamiento mostraron una influencia directa en la dosis de sacarosa utilizada, obteniéndose los mejores resultados con $2 \%$ de sacarosa sin pretratamiento (73,3\%). Las vitroplantas se aclimataron en cilindros a base de turba previamente desinfectados con fungicidas y se colocaron en cámaras húmedas a una temperatura promedio de $20,5^{\circ} \mathrm{C}$ y una humedad relativa de $75,5 \%$ estableciendo ciclos de fertilización semanales. Se obtuvo un $80 \%$ de sobrevivencia a la aclimatación, debido a que algunas plántulas presentaron un estrangulamiento del tallo provocado por un ataque fúngico. Los conidióforos identificados por microscopia óptica y electrónica de barrido mostraron la presencia de Cladosporium spp., el cual fue controlado con las moléculas fungicidas carbendazima e iprodione.
\end{abstract}

Terminos para indexacion - Cydonia oblonga, inmersión temporal, aclimatación de vitroplantas, estrangulamiento en tallo, Cladosporium spp.

\section{QUINCE (Cydonia oblonga) IN VITRO PLANT ROOT FORMATION THROUGH AN AUTOMATED TEMPORARY IMMERSION SYSTEM, AND ITS ACCLIMATION} \begin{abstract}
Cladosporium spp., which was controlled with carbendazim and iprodione fungicides. Cladosporium spp.

${ }^{1}$ (Trabalho 184-14) . Recebido em: 06-06-2014. Aceito para publicação em: 20-05-2015.

${ }^{2}$ M.Sc, Profesora-Investigadora de la Escuela de biología del ITCR. dflores@itcr.ac.cr

${ }^{3}$ M.Eng, Profesor-Investigador de la Escuela de biología del ITCR. rchacon@itcr.ac.cr

${ }^{4}$ Ing, Profesor-Investigador de la Escuela de biología del ITCR. lalvarado@itcr.ac.cr

${ }^{5}$ Lic, Profesor-Investigador de la Escuela de biología del ITCR. aschmidt@itcr.ac.cr

${ }^{6}$ M.Eng, Profesor-Investigador de la Escuela de biología del ITCR. calvarado@itcr.ac.cr
\end{abstract}

ABSTRACT - Quince (Cydonia oblonga) is a non-traditional fruit tree found in Costa Rica that has therapeutic and nutritional properties; however its slow growth and root formation prevents the production of a homogeneous population when using conventional farming techniques. Hence, the aim of this research project was to generate uniform plant material in a reduced time span using a temporary immersion bioreactor system (RITAS $®)$. A semisolid rooting MS culture medium supplemented with $0.1 \mathrm{mg} \mathrm{L}^{-1} \mathrm{NAA} ; 0.3 \mathrm{mg} \mathrm{L}^{-1}$ IBA and 3\% sucrose ( $\mathrm{pH}$ 6.5), developed in the Centro de Investigación en Biotecnología (CIB), Instituto Tecnológico de Costa Rica (ITCR), in Cartago, was used as a reference medium. Four different variations in the sucrose concentration $(1 \%, 2 \%, 3 \%$, and $4 \%$ ) were performed in liquid medium. Each trial was evaluated with in vitro plants which had been previously exposed to the culture medium of the corresponding treatments, in a stationary mode and for a 15 day long period, and with in vitro plants without any previous treatment (a total of eight treatments). The comparison of the root formation percentages evidenced the clear effect of sucrose concentration used, with the best results obtained when using the $2 \%$ sucrose trial with no pre-treatment $(73.3 \%)$. The in vitro plants were acclimated in cylinders made out of peat, have previously been disinfected with fungicide, and placed in a humidity chamber at a $20.5^{\circ} \mathrm{C}$ average temperature and a $75,5 \%$ relative humidity for the establishment of weekly fertilizing cycles. The acclimation process generated an $80 \%$ survival rate, since several seedlings experienced stem strangulation caused by a fungal attack. The conidiophores identified through optical and scanning electron microscopy evidenced the presence of

Index terms - Cydonia oblonga, temporary inmersion, acclimatization of in vitro plants, stem strangulation, 


\section{INTRODUCCIÓN}

El membrillo (Cydonia oblonga), pertenece a la familia de las rosáceas, es un árbol caducifolio, pequeño, de rápida fructificación e importante en las actividades comerciales de países como Turquía, Irán, Argentina y Marruecos (POSTMAN, 2009). Su fruto es utilizado principalmente para el consumo fresco o procesado y como medicina natural debido a sus propiedades astringentes, tónicas y gastrointestinales (ROP et al., 2011; ARLEO, 2011; ROMERO et al., 2009).

La propagación masiva de material vegetal leñoso a través de técnicas convencionales presenta importantes limitaciones, como la lentitud del crecimiento y la dificultad para obtener poblaciones de plantas homogéneas en cuanto a edad y tamaño (MORAGA y CIFUENTES, 2004).

Una solución a esta problemática es la implementación de las técnicas de cultivo in vitro, con el fin de obtener material uniforme, genéticamente idéntico y sano asociado a altas tasas de propagación en tiempos reducidos y en cualquier época del año (CORTEGAZA et al., 2012).

Al igual que la mayoría de especies leñosas, la etapa de enraizamiento in vitro del membrillo es una fase crítica (DOLCET et al., 1990), en donde la respuesta y el desarrollo de las raíces se encuentra directamente influenciado por la calidad del explante, el medio de cultivo, la concentración de azúcares reductores, los reguladores del crecimiento y las condiciones físicas de incubación (URIBE et al., 2012).

Los sistemas de inmersión temporal automatizados presentan ventajas comparativas en contraste con otras técnicas de cultivo de tejidos, que influyen en el enraizamiento in vitro de las plantas, ya que reducen el tiempo de repuesta de las vitroplantas, debido a que existe una absorción más rápida de los nutrientes y de los reguladores del crecimiento (ARAGÓN et al., 2006). Aunado a lo anterior, el uso de tiempos de inmersión controlados, promueven la renovación de la atmósfera dentro del sistema y reducen la posibilidad de hiperhidricidad, lo que incrementa el vigor de las vitroplantas (FLORES et al., 2012).

Por otro lado, la presencia de numerosos estomas poco diferenciados en el envés de las hojas de membrillo con un pobre control sobre la transpiración (SÁNCHEZ, 2011); y la susceptibilidad que presentan las vitroplantas a patógenos durante la fase de aclimatación (MONTOLIU, 2010), representan una etapa crítica que debe ser controlada, por lo que se requiere de entornos ambientales específicos que les permitan superar el estrés generado por las condiciones semiheterótrofas inducidas in vitro para que inicien en los procesos autótrofos normales (POSPÓŠILOVÁ et al., 1999).

Esta investigación tuvo como objetivo el enraizamiento de Cydonia oblonga empleando sistemas de inmersión temporal automatizados $\left(\right.$ RITA $\left.^{\circledR}\right)$, con el fin de contribuir a la estrategia nacional de diversificación agrícola.

\section{MATERIALES Y MÉTODOS}

\section{Enraizamiento in vitro}

Se evaluó la eficiencia de la RITA $^{\circledR}$ al utilizar como referencia un medio semisólido Murashige y Skoog (MS) (1962), suplementado con 0,1 mg L-1 de ácido naftalenacético (ANA); $0,3 \mathrm{mg} \mathrm{L}^{-1}$ de ácido indolbutírico (AIB) y 3\% de sacarosa a un $\mathrm{pH}$ de 6,5; desarrollado por el Centro de Investigación en Biotecnología (CIB) del Instituto Tecnológico de Costa Rica (ITCR) para la producción de material vegetal de $C$. oblonga, donde se reportan porcentajes de enraizamiento de hasta un 54,3 $\pm 4,04$.

Se ensayaron cuatro variaciones en la concentración de sacarosa $(1 \%, 2 \%, 3 \%$ y 4\%). Cada ensayo fue evaluado con vitroplantas previamente expuestas al medio correspondiente empleado en los tratamientos, de forma estacionaria por un período de 15 días, y con vitroplantas sin tratamiento previo, para un total de ocho tratamientos.

Se colocaron $200 \mathrm{~mL}$ de medio de cultivo por RITA $^{\circledR}$. La densidad de siembra empleada fue de 15 vitroplantas (2,5 cm de longitud) por recipiente. El periodo de inmersión fue de $10 \mathrm{~min}$, con una frecuencia de tres veces al día (cada $8 \mathrm{~h}$ ). Se trabajó con un $n=45$ vitro-plantas distribuídas en tres repeticiones, se incubaron por un tiempo de 60 días a $26{ }^{\circ} \mathrm{C}$ y un fotoperiodo de $16 \mathrm{~h}$ luz. Se evaluó el porcentaje de enraizamiento aplicando la fórmula, además los parámetros de número promedio de raíces, longitud promedio de raíces principales y longitud promedio del tallo de las vitroplantas para las plántulas enraizadas.

\section{Análisis Estadístico}

En la comparación del porcentaje de enraizamiento entre los tratamientos y con respecto al medio semisólido del CIB, se realizó un análisis de varianza mediante la prueba de Fisher $(\alpha=0,05)$.

Para determinar la influencia de la concentración de sacarosa y el pretratamiento en los parámetros de número promedio de raíces, longitud promedio de raíces principales y longitud promedio del tallo de las vitroplantas enraizadas, se 
realizó un diseño completamente aleatorio del tipo factorial de dos factores con niveles fijos y se analizó mediante un Modelo Lineal General (GLM), prueba $F(\alpha=0,05)$ del tipo $y_{i j k}=\mu+\tau_{i}+\beta_{j}+(\tau \beta)_{i j k}+\varepsilon_{i j k}$; donde $y=$ número promedio de raíces, longitud promedio de raíces principales o longitud promedio del tallo; $\mu=$ promedio de muestra; $\tau=\%$ de sacarosa con $i$ $=1,2,3,4$ niveles; $\beta=$ Pretratamiento con $j=S i$, No niveles; $k=18$ ( 3 repeticiones de 6 réplicas promedio/ combinación) y $\varepsilon=$ error.

Cuando los parámetros mostraron términos significativos en los factores principales se analizaron los promedios mediante Pruebas de Fisher $(\alpha=0,05)$. Se comprobaron los supuestos estadísticos de homocedasticidad, normalidad de residuos y aleatorización para las pruebas estadísticas.

\section{Aclimatación en Invernadero}

Para esta etapa se utilizaron plántulas provenientes del mejor tratamiento de enraizamiento. Se inocularon en cilindros a base de turba previamente hidratados con un fungicida que contenía carbendazima e iprodione como ingredientes activos. Fueron rociadas con un bioestimulante a base de macroelementos, microelementos, tiamina, fitohormonas y un estabilizador de $\mathrm{pH}$. Se mantuvieron en cámaras húmedas a una temperatura promedio de $20,5{ }^{\circ} \mathrm{C}$ y una humedad relativa de $75,5 \%$. La sobrevivencia se evaluó durante un período de cuatro semanas.

Posteriormente se transfirieron a un sustrato compuesto por suelo y granza (3:1), previamente desinfectado con el mismo fungicida utilizado para desinfectar los cilindros a base de turba. Durante toda esta etapa se realizaron ciclos de fertilización semanales, empleando extractos de algas, sales minerales y aminoácidos.

Debido a la aparición de un estrangulamiento en los tallos de membrillo a causa de un hongo se realizó la identificación de las estructuras reproductivas mediante el análisis en microscopia óptica y microscopia electrónica de barrido (MEB) con el fin de seleccionar un ingrediente activo efectivo. Para la observación en microscopía óptica, se utilizó safranina como agente de tinción con el fin de obtener mejor calidad en las imágenes.

\section{RESULTADOS}

\section{Enraizamiento in vitro}

La comparación de los porcentajes de enraizamiento entre los tratamientos evaluados con respecto al medio semisólido desarrollado en el CIB mostraron una influencia directa en la dosis de sacarosa utilizada, obteniéndose los mejores promedios de enraizamiento en los ensayos con $2 \%$ de sacarosa, superando el medio estándar de enraizamiento del CIB (Tabla 1).

Los tratamientos evaluados en RITA $^{\circledR}$ presentaron diferentes comportamientos para los parámetros, pese a que el enraizamiento in vitro se logró en todos los casos. El análisis del GLM permitió determinar para el número promedio de las raíces que la concentración de sacarosa influyó significativamente $(\mathrm{p}<0,05)$ en la respuesta (\% de la suma de los cuadrados $\left.\left(\% S C_{\text {sacarosa }}\right)=10,8 \%\right)$, mientras que el pretratamiento lo hizo sobre la longitud promedio de las raíces principales $\left(\% S C_{\text {pretratamiento }}=9,67 \%\right)$ y ambos factores principales sobre la longitud promedio del tallo $\left(\% S C_{\text {pretratamiento }}=18,26 \% ; \% S C_{\text {sacarosa }}=18,97 \%\right)$, no así la interacción de estos factores cuyo aporte a la variabilidad del análisis general fue insignificante. El termino del error cubrió un $90 \%$ en el caso del número promedio de raíces, un $85,75 \%$ para la longitud promedio de estas raíces y un $62 \%$ de la variabilidad de los datos para la longitud promedio del tallo.

Por otro lado, cuando se evaluaron los tratameintos para diferencias de medias, a pesar de no encontrar diferencias significativas en la mayoría de las variables en estudio, se determinó que el ensayo con $2 \%$ de sacarosa sin pretratamiento presentó los mejores porcentajes de plantas enraizadas y cantidad promedio de raíces (Tabla 2), aunado a características fenotípicas deseables para el proceso de aclimatación.

\section{Aclimatación en Invernadero}

Las vitroplantas provenientes del ensayo con $2 \%$ de sacarosa sin pretratamiento, se adaptaron a las condiciones ex vitro, mostrando un buen desarrollo apical y radicular luego de seis semanas de aclimatación (Figura 1).

A la tercera semana se obtuvo un $80 \%$ de sobrevivencia a la aclimatación, ya que algunas plántulas presentaron un estrangulamiento del tallo provocado por un hongo, lo que impidió el transporte de agua y nutrientes a la parte aérea de la planta (Figura 2a). Los conidióforos identificados en microscopia óptica (Figura 2b) y electrónica de 
barrido (Figura 2c), obtenidos a partir del hongo aislado de tallos afectados, mostraron un porte erecto, con dos o tres ramificaciones, en donde se localizan las esporas, las cuales tienen formas ovoides, cilíndricas o irregulares con una cavidad en el centro y en algunos casos presentaron extremos punteados. En microscopía óptica, tanto los conidióforos como las esporas mostraron una coloración marrón pálida.

\section{DISCUSIÓN}

\section{Enraizamiento in vitro}

La rizogénesis es el resultado de la interacción de múltiples factores bioquímicos y ambientales, que desencadenan procesos morfogénicos dentro de las plantas. No todas las vitroplantas presentan la capacidad de enraizar de manera espontánea bajo condiciones in vitro (SALISBURY Y ROOS, 1994). Es en estos casos, que la incorporación de reguladores de crecimiento a los medios de cultivo se hace necesaria, para que en conjunto con los niveles endógenos de hormonas, se alcancen las concentraciones sinérgicas favorables que den inicio a los procesos organogénicos (SINHA, 2004; SANTELICES y GARCÍA, 2003).

Las auxinas son los reguladores de crecimiento más descritos en procesos de rizogénesis in vitro, presentando efectos tanto a nivel radical como apical, donde el crecimiento de las vitroplantas es inducido mediante mecanismos de elongación celular, producto de la capacidad acarreadora de nutrientes y metabolitos por parte de estas moléculas (SINHA, 2004).

Según Uribe et al. (2012), la utilización de bajas dosis de auxinas sintéticas, como el AIB, $\mathrm{y}$ en menos frecuencia ANA, son más eficientes que el empleo de hormonas naturales, debido a que la permanencia libre de estas moléculas en los medios de cultivo es escasa, ya que son modificadas bioquímicamente para promover una respuesta sostenida del enraizamiento. Esto concuerda con los resultados obtenidos, en donde el enraizamiento in vitro se logró en todos los casos (Tablas 1 y 2) utilizado una combinación de estos reguladores en bajas concentraciones También Thakur y Kanwar (2008) reportan porcentajes de enraizamiento de hasta un $81,47 \%$ en plantas de Pyrus pyrifolia empleando AIB y ANA en una concentración de $0,25 \mathrm{mg} \mathrm{L}^{-1}$.

Los ensayos realizados en RITA $^{\circledR}$, presentaron un mejor desarrollo fenotípico en comparación con las vitroplantas obtenidas en el medio semisólido, razón por la cual se descarta la posibilidad de efectos adversos en el crecimiento por excesiva oxigenación y remoción de $\mathrm{CO}_{2}$ y otros gases volátiles propuesta por Perugorría (2011). Aunado a esto, Aragón et al. (2006) establecen que la aplicación de auxinas en medios de cultivo líquidos en sistemas de inmersión temporal, favorecen el vigor de las plantas facilitando el manejo del material en etapas posteriores, por lo que esta diferencia en el promedio de enraizamiento puede estar más relacionada a un estado fisiológico de las vitroplantas.

Por otro lado, Castro y González (2002) mencionan que las condiciones in vitro en que se incuban las vitroplantas juegan un papel determinante en el fenotipo del explante, ya que las variaciones en la intensidad lumínica, la temperatura, el porcentaje de humedad relativa y las concentraciones de sales minerales, inducen en los explantes el desarrollo de un metabolismo semiheterótrofo, factor causante de dificultades en el desarrollo de características fenotípicas deseables en las vitroplantas para las etapas posteriores, por lo que es necesario el desarrollo de estrategias que imiten las condiciones de propagación convencional del material a la hora de manipularlo in vitro.

Las RITAs ${ }^{\circledR}$ brindan condiciones que benefician el enraizamiento en muchas especies, ya que hacen disponible con mayor facilidad el medio de cultivo al explante, manteniendo una mayor área superficial en contacto. Por otro lado, la capacidad de renovación atmosférica dentro del sistema, reduce los problemas de hiperhidricidad y la acumulación excesiva de gases que puedan interferir en el adecuado desarrollo de las plantas. Además permiten el ingreso de $\mathrm{CO}_{2}$ que en conjunto con la luz controlada promueven procesos fotosintéticos que inducen al desarrollo de características anatómicas y fisiológicas, semejando las condiciones metabólicas de las plantas ex vitro (CEJAS et al., 2011; ARAGÓN et al., 2006). Esto concuerda con Castro (2006), quién reportó en Rubus idaeus L. diferencias significativas en el fenotipo de vitroplantas propagadas en RITA $^{\circledR}$, con respecto a vitroplantas expuestas al mismo medio en semisólido.

Otro factor que influye en los resultados analizados para determinar la eficiencia del enraizamiento in vitro en RITA $^{\circledR}$ fue la sacarosa, capaz de variar las respuestas de crecimiento y enraizamiento en las vitroplantas, donde al incrementar los niveles de sacarosa causa efectos negativos en los procesos rizogénicos, mientras que existe un mayor desarrollo y elongación del explante al existir mayor fuente de carbono (PAZ y VILLEGAS, 2009). Esto se comprobó con el análisis factorial donde la sacarosa influyó como determinante significativo tanto para el número 
promedio de las raíces como para la longitud promedio del tallo.

Además, la reducción de sacarosa en el medio de cultivo ejerce un estrés fisiológico que induce a la formación de raíces en busca de posibles fuentes de nutrientes físicamente alejados, razón por la cual se acelera el desarrollo radicular, reduciendo el crecimiento apical a causa de variaciones en el potencial osmótico que reduce la entrada de nutrientes en la vitroplanta (SAWWAN et al., 1998). Esto además concuerda con los resultados mostrados en el Tabla 2, donde se refleja la influencia directa de la concentración de sacarosa sobre el enraizamiento in vitro, ya que los mejores resultados se lograron empleando el medio de cultivo suplementado con $2 \%$ de sacarosa.

Sin embargo, D'onofrio y Morini (2005) determinaron que un bajo promedio en la longitud de raíces se debe al mayor gasto energético ocasionado por la producción de raíces y el mantenimiento apical, lo que favorece la aclimatación.

El pretratamiento realizado presentó en la mayoría de los casos, menores porcentajes de enraizamiento que los mismos ensayos sin el pretratamiento, ya que probablemente la concentración de auxinas dentro de las vitroplantas aumentó, producto del rápido subcultivo realizado al pasar del medio de enraizamiento en tubos de ensayo a RITA $^{\circledR}$, esto concuerda con Uribe et al. (2012) ya que establece que las auxinas en altas concentraciones presentan efectos antagonistas en la rizogénesis. Lo anterior concuerda con el análisis factorial para el pretratamiento, donde influenció significativamente la longitud promedio de las raíces y la longitud promedio del tallo, procesos regulados por las variaciones en las concentraciones de auxinas.

\section{Aclimatación en Invernadero}

A pesar de la calidad del material vegetal obtenido en la etapa in vitro, se conoce que estas plantas presentan hojas con cutículas delgadas, poca funcionalidad estomática, células del mesófilo de empalizada desorganizadas y modificaciones en el sistema vascular, características que influyen directamente en la supervivencia en invernadero (SÁNCHEZ, 2011). Debido a lo anterior, fue de vital importancia el control de la humedad relativa y la intensidad lumínica, Nieto y Valdivieso (2013), recomiendan disminuir progresivamente la humedad e incrementar la luminosidad en temperaturas moderadas, evitando así, la transpiración excesiva con el fin de lograr mayores porcentajes de sobrevivencia.

Por otro lado, la aplicación semanal de polisacáridos fácilmente asimilables, aminoácidos y microelementos como el boro, cobre, manganeso, molibdeno y zinc, facilitan el endurecimiento y la aclimatación de las plántulas, reduciéndo el estrés en esta etapa (NIETO Y VALDIVIESO, 2013). De esta manera fue posible lograr buenos rendimientos en la aclimatación, con un buen desarrollo (Figura 1). No obstante, también las plantas se enfrentan a ataques de patógenos (Figura 2a), razón por la cual es importante el control previo mediante procedimientos de desinfección de sustratos y aplicaciones periódicas de agroquímicos, para prevenir la pérdida del material (MURILLO Y BADILLA, 2005). En los ensayos realizados, la aplicación de fungicidas sistémicos y de contacto contribuyó a obtener un porcentaje de sobrevivencia de hasta un $80 \%$.

Por otro lado, las características descritas del hongo aislado a partir de la podredumbre del tallo en membrillo (Figuras $2 \mathrm{~b}$ y $2 \mathrm{c}$ ), muestran semejanza con las estructuras reproductivas del género Cladosporium, descrito por Watanabe (2002), el cual es caracterizado por ser un género muy versátil, de rápido crecimiento, en donde una gran cantidad de especies son consideradas fitopatogenas, con capacidad para crecer en un amplio espectro de temperaturas $\left(18-28^{\circ} \mathrm{C}\right)$, y en presencia de una alta humedad relativa (BORREGO, 2012). Probablemente la aparición de la sintomatología inició en las primeras semanas de la aclimatación, en donde se mantuvieron los mayores porcentajes de humedad con el fin de evitar transpiración excesiva en las vitroplantas.

Según Fernández et al. (2012), el estrangulamiento del tallo se da debido a que las esporas se establecen en superficies húmedas, germinando y formando una red de hifas que penetran la epidermis o los estomas, afectando el transporte acrópeto y basípeto de sustancias, y el soporte del área foliar.

Para el control de Cladosporium spp. se utilizaron las moléculas iprodione, como fungicida de contacto de amplio espectro, que afecta todas las fases del ciclo de desarrollo de los hongos patógenos, y carbendazima como una molécula sistémica con acción protectora y curativa que afecta los tubos germinativos y el crecimiento del micelio (MSDS). 
TABLA 1- Comparación de medias entre los tratamientos en el membrillo (Cydonia oblonga) evaluados con respecto al medio semisólido de enraizamiento del Centro de Investigación en Biotecnología (CIB).

\begin{tabular}{|c|c|c|}
\hline \multicolumn{2}{|c|}{ Tratamientos } & $\begin{array}{c}\% \text { Enraizamiento } * \\
(\text { Desviación Estándar agrupada } \pm 20,59)\end{array}$ \\
\hline$\%$ Sacarosa & \multicolumn{2}{|l|}{ Pretratamiento } \\
\hline \multirow{2}{*}{$1 \%$} & $\mathrm{NO}$ & $38,3 \mathrm{c}$ \\
\hline & SI & $13,3 \mathrm{e}$ \\
\hline \multirow{2}{*}{$2 \%$} & $\mathrm{NO}$ & $73,3 \mathrm{a}$ \\
\hline & SI & $65,0 \mathrm{a}$ \\
\hline \multirow{2}{*}{$3 \%$} & $\mathrm{NO}$ & $26,7 \mathrm{~d}$ \\
\hline & SI & $40,4 \mathrm{c}$ \\
\hline \multirow{2}{*}{$4 \%$} & $\mathrm{NO}$ & $26,7 \mathrm{~d}$ \\
\hline & SI & $26,7 \mathrm{~d}$ \\
\hline io semisólido & & $54,3 \mathrm{~b}$ \\
\hline
\end{tabular}

*Letras diferentes indican diferencia estadística significativa entre los tratamientos ( $<<0,05)$, según el Análisis de Varianza y la Prueba de Fisher, $\alpha=0,05$.

TABLA 2- Parámetros evaluados para determinar la eficiencia del enraizamiento in vitro en el membrillo (Cydonia oblonga).

\begin{tabular}{|c|c|c|c|c|}
\hline \multicolumn{2}{|c|}{ Tratamientos } & \multicolumn{3}{|c|}{ Variables evaluadas* } \\
\hline$\%$ Sacarosa & Pre-tratamiento & $\begin{array}{c}\text { Número promedio } \\
\text { de las raíces }\end{array}$ & $\begin{array}{l}\text { Longitud promedio } \\
\text { de las raíces }(\mathrm{cm})\end{array}$ & $\begin{array}{l}\text { Longitud promedio } \\
\text { del tallo }(\mathrm{cm})\end{array}$ \\
\hline \multirow{2}{*}{$1,0 \%$} & NO & $2,70 \pm 1,64 \mathrm{ab}$ & $0,95 \pm 0,16 \mathrm{c}$ & $4,39 \pm 1,87 d$ \\
\hline & SI & $2,50 \pm 2,51 \mathrm{ab}$ & $1,13 \pm 0,24 \mathrm{ab}$ & $7,02 \pm 2,17 \mathrm{c}$ \\
\hline \multirow{2}{*}{$2,0 \%$} & $\mathrm{NO}$ & $3,39 \pm 2,66 \mathrm{a}$ & $0,98 \pm 0,14 \mathrm{bc}$ & $5,10 \pm 1,92 \mathrm{~d}$ \\
\hline & SI & $3,39 \pm 2,12 \mathrm{a}$ & $1,09 \pm 0,20 \mathrm{abc}$ & $7,32 \pm 1,74 \mathrm{c}$ \\
\hline \multirow{2}{*}{$3,0 \%$} & NO & $2,42 \pm 1,73 \mathrm{ab}$ & $1,02 \pm 0,18 \mathrm{abc}$ & $6,94 \pm 3,57 \mathrm{c}$ \\
\hline & SI & $1,72 \pm 0,96 \mathrm{~b}$ & $1,15 \pm 0,18 \mathrm{a}$ & $10,36 \pm 2,44 \mathrm{a}$ \\
\hline \multirow{2}{*}{$4,0 \%$} & $\mathrm{NO}$ & $1,00 \pm 0,00 \mathrm{~b}$ & $1,10 \pm 0,26 \mathrm{abc}$ & $7,05 \pm 3,47 \mathrm{c}$ \\
\hline & SI & $2,00 \pm 1,20 \mathrm{ab}$ & $1,15 \pm 0,20 \mathrm{a}$ & $9,21 \pm 3,06 b$ \\
\hline
\end{tabular}

*Letras diferentes indican diferencia estadística significativa entre los tratamientos ( $<<0,05)$, según el Análisis de Varianza y la Prueba de Fisher, $\alpha=0,05$. 

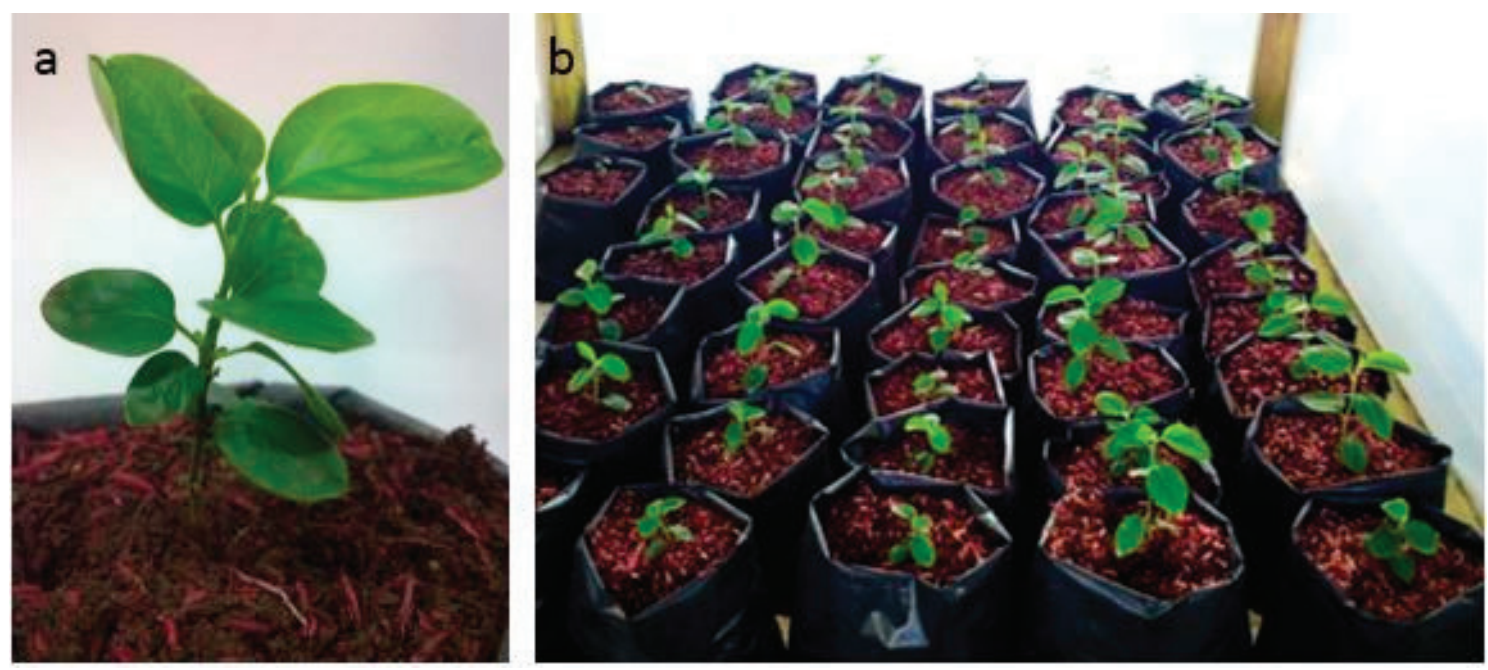

FIGURA 1- Aclimatación de plántulas de membrillo (Cydonia oblonga). (a). Desarrollo de la vitroplanta luego de seis semanas de aclimatación. (b) Plántulas aclimatadas.
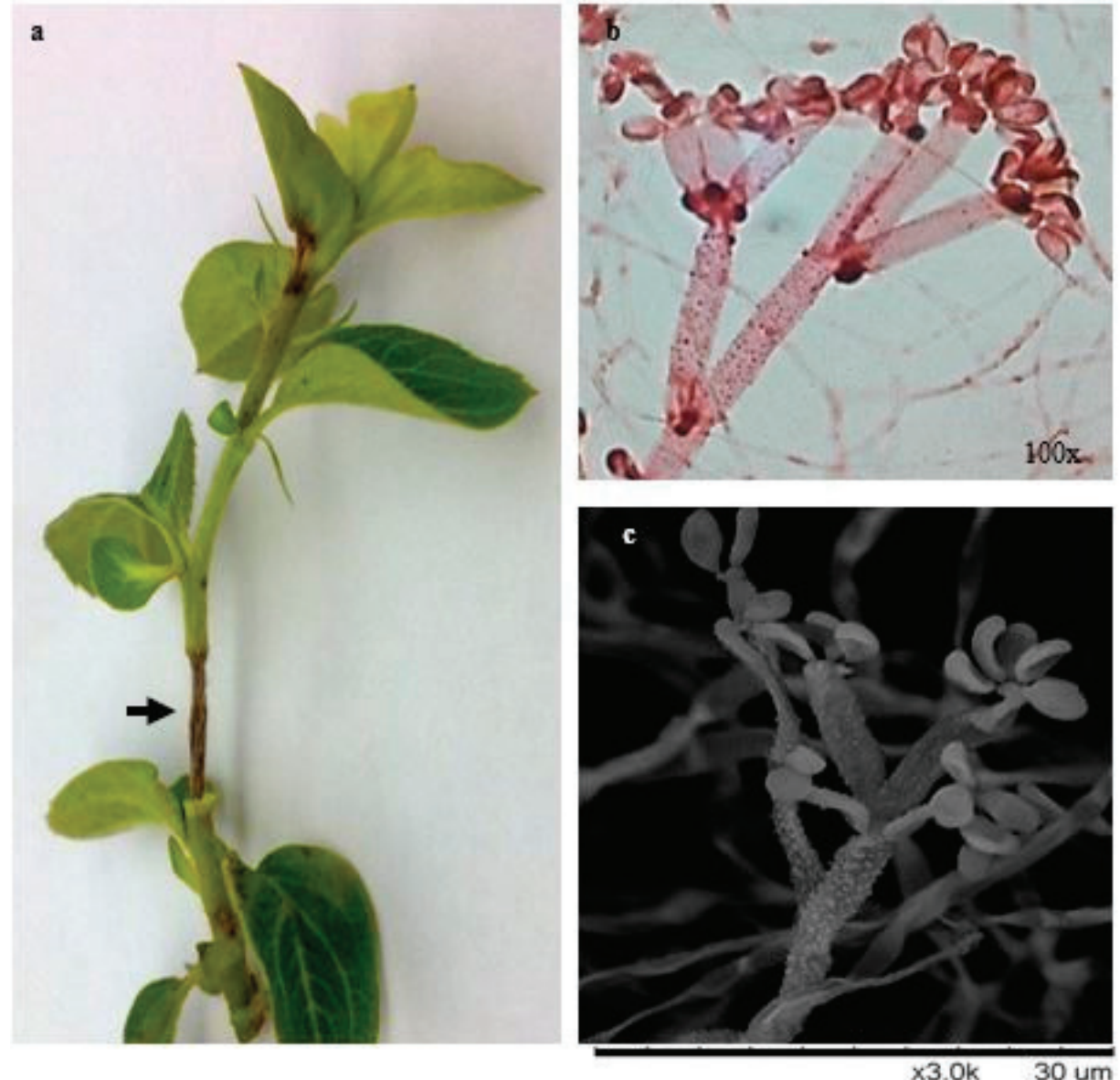

FIGURA 2- Planta de membrillo (Cydonia oblonga) infectada e identificación de esporas fúngicas. (a) Estrangulamiento del tallo de membrillo por ataque fúngico. Conidióforos del hongo causante del estrangulamiento del tallo visto en microscopia óptica (b), y en MEB (c). 


\section{CONCLUSIONES}

A partir de los ensayos realizados se determinó que con la disminución del porcentaje de sacarosa hasta un $2 \%$ se obtienen mejores rendimientos en el enraizamiento in vitro del membrillo $(C$. oblonga), donde menores concentraciones afectan los procesos rizogénicos de las plantas positiva y significativamente. Por otro lado, la aplicación de fertilizantes y fungicidas facilitaron la aclimatación de las plántulas, reduciéndose el estrés bioquímico y ambiental generado en esta etapa.

\section{AGRADECIMIENTOS}

Los autores agradecen a la Vicerrectoría de Investigación y Extensión del Instituto Tecnológico de Costa Rica por el financiamiento del presente proyecto.

\section{REFERENCIAS}

ARAGÓN, C.; ESCALONA, M.; CAPOTE, I.; CEJAS, I.; RODRÍGUEZ, R.; SANDOVAL, J.; ROELS, S.; DEBERGH, P.; GONZÁLEZ, J. Aspectos metabólicos del crecimiento y desarrollo de plántulas de plátano (CEMSA $3 / 4$ ) micropropagados en Biorreactores de Inmersión Temporal BIT. Cultivos Tropicales, San Jose, v.27, n.1, p.39-44, 2006.

ARLEO, M. Identificación de especies vegetales en el dulce de membrillo mediante análisis molecular. 2011. 53 f. Tesis (Licenciado en Bioquímica) Universidad de la Republica, Montevideo, 2011.

BORREGO, S. Cladosporium: género fúngico que deteriora soportes documentales y afecta a la salud del hombre. Boletín del Archivo Nacional, Habana, v.20, p.104-118, 2012.

CASTRO, F. Estableciemiento in vitro $\mathbf{y}$ micropropagación de frambuesa (Rubus idaeus L.) utilizando medio semisólido y medio líquido en RITA.2006. 51 f. Tesis (Grado de Ing. en Biotecnología) - Instituto Tecnológico de Costa Rica, Cartago, 2006.

CASTRO, D.; GONZÁLEZ, J. Eucalyptus (Eucalyptus grandis Hill ex Maiden) micropropagation in a temporary immersion system. Agricultura Técnica, Santiago, v.62, n.1, p.68-78, 2002.
CEJAS, I.; CAPOTE, I.;ARAGÓN, C.; ESCALONA, M.; PINA, D.; GONZÁLEZ, J.; RODRÍGUEZ, R.; NOCEDA, C.; CAÑAL, M.; SANDOVAL, J.; ROELS, S.; DEBERGH, P. Optimización del protocolo de propagación del plátano $\mathrm{cv}$. CEMSA $3 / 4$ en Biorreactores de Inmersión Temporal. Agrociencia Uruguay, Montevideo, v.15, n.1, p.13$18,2011$.

CORTEGAZA, L.; CABRERA, L.; SANTANA, $O$. El cultivo in vitro aplicado al mejoramiento genético: la aplicación de las técnicas de cultivo in vitro constituyen una herramienta novedosa para el mejoramiento genético. Editorial Academica Española, 2012. 56p.

DOLCET, R.; MOK, D.; MOK, M. Micropropagation of Pyrus and Cydonia and their responses to Felimiting conditions. Plant Cell, Tissue and Organ Culture, Dordrecht, v.21, p.191-199, 1990.

D'ONOFRIO, C.; MORINI, S. Development of adventitious shoots from in vitro grown Cydonia oblonga leaves as influenced by different cytokinins and treatment duration. Biologia Plantarum, Dordrecht, v.49, n.1, p.17-21, 2005.

FERNÁNDEZ, J.; MARTÍNEZ, J.; HERNÁNDEZ, M. Evaluación de la ultraestructura de las bayas de uva de mesa y sus alteraciones mediante criomicroscopia electrónica de barrido. Vitae, San Juan, v.19, n.1, p.366-369, 2012.

FLORES, D.; CHACÓN, R.; JIMÉNEZ, V.; ORTIZ, F. Enraizamiento de mora (Rubus adenotrichus) en medio líquido en el sistema de inmersión temporal y su aclimatación en invernadero. Tecnología en Marcha, Cartago, v.25, n.2, p.3-9, 2012.

MONTOLIU, A. Respuesta fiisiológica de los cítricos sometidos a condiciones de estrés biótico y abiótico. Aspectos comunes y específicos. 2010. 196 f. Tesis (Grado de Doctor en Ingeniería Agrónoma) - Universidad Jaume I, Castellón, 2010.

MORAGA, M.; CIFUENTES, L. Aplicación de técnicas de cultivo in vitro en la propagación de Legrandia concinna. Revista Bosque, Valdivia, v.25, n.1, p.129-135, 2004.

MURASHIGE, T.; SKOOG, F. A revised medium for rapid growth and bioassays with tobacco tissue cultures. Physiology Plantarum, Copenhagen, v.15, n.3, p.473-497, 1962. 
MURILLO, O.; BADILLA, Y. Enraizamiento de estacas de especies forestales. Revista Forestal, Rio de Janeiro, v.2, n.6, p.1-6, 2005.

NIETO, V.; VALDIVIESO, M. Establecimiento de un protocolo de regeneración in vitro $\mathrm{y}$ aclimatación para Fuchsia pilaloensis y Fuchsia hybrida para su conservación. 2013. $105 \mathrm{f}$. Tesis (Ingeniero en Biotecnología) - Universidad Politécnica Salesiana, Quito, 2013.

PAZ, R.; VILLEGAS, A. Niveles de sacarosa en el enraizamiento in vitro y aclimatación ex vitro de plántulas del portainjerto de VID R110 (Vitis rupestris $\mathrm{x}$ Vitis berlandieri). Interciencia, Caracas, v.34, n.12, p.897-902, 2009.

PERUGORRÍA, M. Desarrollo de una técnica para micropropagación de especies leñosas en birreactores. 2011. 76 f. Tesis (Grado de Master en Biotecnología) - Universidad de la Republica, Montevideo, 2011.

POSPÓŠILOVÁ, J.; TICHÁ, I.; KADLECEK, P.; HAISEL, D.; PLZÁKOVÁ, S. Aclimatization of micropropagated plants to ex vitro conditions. Biología Plantarum, Dordrecht, v.42, n.4, p.481497, 1999.

POSTMAN, J. Cydonia oblonga: The unappreciated quince. Arnoldia, Boston, v.67, n.1, p.2-9, 2009.

ROMERO, M.; DÁVILOS, H.; ASTUDILlO, A. Actividad gastrointestinal del fruto de Cydonia oblonga Miller. Revista Latinoamericana Química, Monterrey, v.37, n.2, p.115-121, 2009.

ROP, O.; BALIK, J.; REZNICEK, V.; JURIKOVA, T.; SKARDOVA, P.; SALAS, P.; SOCHOR, J.; MLCEK, J.; KRAMAROVA, D. Chemical characteristics of fruits of some selected quince (Cydonia oblonga Mill.) cultivars. Czech Journal of Food Sciences, Praha, v.29, n.1, p.65-73, 2011.
SALISBURY, F.; ROOS, C. Fisiología vegetal. Desarrollo vegetal. Mexico: Grupo Editorial Iberoamérica, 1994. p. 363-591.

SÁNCHEZ, S. Estudio investigativo del membrillo, análisis de sus propiedades, recuperación de su uso y aplicación gastronómica en cocina fusión y molecular. 2011. 106 f. Tesis (Administrador Gastronómico) - Universidad Tecnológica Equinoccial, Quito, 2011.

SANTELICES, R.; GARCÍA, C. Effects of indolebutyric acid and stem position on cuttings collected from stump sprouts of Nothofagus alessandrii Espinosa. Bosque, Valdivia, v.24, n.2, p.53-61, 2003.

SAWWAN, J.; ABU-QAOUD, H.; HOZAIN, M. Effect of sucrose level on in vitro and ex vitro growth of African violet (Saintpaulia ionantha Wendl). Advances in Horticultural Science, Firenze, v.12, p.8-10, 1998.

SINHA, R. Modern plant physiology: hormones/ growth regulator. Oxford: Alpha Science International, 2004. p.461-472.

THAKUR, A.; KANWAR, J. Micropropagation of "Wild pear" Pyrus pyrifolia (Burm F.) Nakai. II. Induction of Rooting. Notulae Botanicae Horti Agrobotanici, Cluj- Napoca, v.36, n.2, p.104-111, 2008.

URIBE, M.; ULLOA, J.; DELAVEAU; C.; SÁEZ, K.; MUNÓZ, F.; CARTES, P. Influence of auxins on in vitro rooting of microshoots of Nothofagus glauca (Phil.) Krasser. Gayana Botánica, Concepción, v.69, n.1, p.105-112, 2012.

WATANABE, T. Soil and seed fungi: morphologies of cultured fungi and key to species. $2^{\text {nd }}$ ed. Boca Raton: CRC Press, 2002. 486p. 